\title{
Perbandingan Kuat Tekan Beton Antara Campuran Aggregat Kasar Batu Pecah (Split) Dengan Batu Alam Palembayan Untuk Beton Struktur
}

\author{
Masril \\ Dosen Tetap FT . UMSB \\ Email : mril6030@gmail.com
}

\begin{abstract}
Abstrak: Kekuatan beton sekarang ini sangat dipengaruhi oleh bahan dan material yang digunakan serta dilatar belakangi oleh dua jenis aggregat kasar dan mutu beton yang dipakai untuk struktur bangunan. Sehingga mampu memenuhi kebutuhan struktur saat ini.

Pemilihan material beton dilakukan untuk menentukan kekuatan karakteristik dari struktur beton itu sendiri, material dari aggregat kasar yang dipergunakan aggregat kasar batu pecah (split) dan aggregat kasar batu alam kemudian yang sangat menentukan sekali adalah aggregat halus.

Dalam penelitian perbandingan campuran beton memakai aggregat halus pasir murni dengan membandingkan aggregat halus yang dicampur dengan debu batu bara dengan porsentase campurannya $1 \%, 2 \%, 5 \%, 10 \%$ dan 15\% , kemudian diukur nilai slump dengan dengan air yang bervariasi dan air untuk $1 \mathrm{~m} 3$ campuran membutuhkan air yang maksimalnya sekitar 259 liter, masing-masing dilakukan pengujian terhadap benda uji berbentuk selinder pada umur 7 hari, 14 hari, 21 hari dan 28 hari, dan analisa akhir pada penelitian ini adalah umur 28 hari, ternyata campuran beton aggregat halus dicampur dengan debu batu bara lebih tinggi kuat tekan beton struktur, pada mutu beton rencana yang sama (K 250), dengan selisih pebedaan sekitar 5\%.
\end{abstract}

\section{Kata Kunci : Uji Kuat Tekan Beton}

Abstract: The strength of concrete is now strongly influenced by the materials and materials used and backdropped by two types of coarse aggregates and concrete quality used for building structures. So as to meet the needs of the current structure.

The selection of the concrete material is carried out to determine the characteristic strength of the concrete structure itself, the material of coarse aggregates employed by crude aggregates of split rock and rough aggregates of natural stones then of greatest determination are fine aggregates.

In the comparative study the concrete mixture uses fine aggregate of pure sand by comparing the fine aggregate mixed with coal dust with mixed percentage of $1 \%, 2 \%, 5 \%, 10 \%$ and $15 \%$, then measured slump value with varying water and water for $1 \mathrm{~m} 3$ mixture requires maximum water of about 259 liters, each tested on cylindrical test specimen at 7 days, 14 days, 21 days and 28 days, and final analysis in this study is 28 days, it turns out a fine aggregate concrete mixture mixed with coal dust higher compressive strength of concrete, on the same concrete plan quality (K 250), with difference of about $5 \%$ difference.

Keywords : Strong Pressure Concrete Test

\section{I . PENDAHULUAN}

\section{A . Latar Belakang}

Untuk bangunan teknis maka material harus mempunyai sifat tahan terhadap pengaruh cuaca dan kekuatannya memenuhi.karakteristik perencanaan yang dipakai sebagai dasar perhitungan.

Pada umumnya para pekerja cendrung untuk mengerjakan pekerjaan dengan baik, tetapi sering terjadi adanya keinginan untuk mendapatkan hasil yang banyak sehingga melupakan persyaratan teknis konstruksi yang di syaratkan. Sebagai alat kontrol maka fungsi laboratorium akan selalu dapat dipakai sebagai pedoman untuk mengendalikan mutu, tanpa harus membuat suatu konstruksi yang mempunyai yang sangat berlebihan 


\section{B . Rumusan Masalah}

Dalam penelitian ini penulis hanya meneliti perbandingan kuat tekan beton antara campuran aggregat kasar batu pecah (split) ukuran $2 / 3 \mathrm{~cm}$ dengan aggregat kasar dari batu alam untuk mutu beton K. 250, ini akan sangat erat hubungannya dengan pelaksanaan pekerjaan beton bertulang nantinya.

\section{C.Maksud dan Tujuan Penelitian}

tujuan dan maksud penulisan ini adalah menentukan perbandingan kuat tekan beton antara campuran aggregat kasar batu pecah (split) dengan batu alam untuk beton struktur, disamping itu penulis ingin mengetahui lebih dekat lagi penerapan teori-teori yang perkuliahan dengan pelaksanaan yang sebenarnya. Dengan penulisan ini agar menambah ilmu dan pengalaman terutama bagi penulis sendiri

\section{Ruang lingkup/batasan penelitian}

Dalam menganalisa Agregat kasar penulis membatasi masalah yang akan dibahas pada penelitian ini adalah Hanya Menghitung kuat tekan beton mutu beton dengan mebandingkan kekuatan dengan memakai split dan agregat batu alam .

\section{II . KAJIAN PUSTAKA}

Untuk kepentingan pelaksanaan pembangunan secara umum, pengunaan agregat dilapangan dapat diyakini setelah melaui kegiatan pengujian seperti :

1. Pemeriksaan Berat Volume.

Pegujian ini untuk menentukan berat isi agregat atau campuran yang didefinisikan sebagai perbandingan antara berat material kering dengan volumenya.

2. Analisa saringan agregat

Menentukan pembagi butir (gradasi) agregat . Data Distribusi butiran pada agregat diperlukan dalam perencanaan adukan beton. Pelaksanaan Penentuan gradasi ini dilakukan pad agregat kasar

3. Analisis Specific - Grafity dan penyerapan agregat Kasar.pegujian ini untuk menentukan Bulk dan Apparent specific garfity dan penyerapan ( absorption ) dari agregat menurut prosedur ASTM C 127, Nilai ini diperlukan untuk menetapkan besarnya komposisi volume agregat dalam adukan beton.

4. Agregat Klas B.

Menggunakan Kerikil ( grogol) yang dipecahkan dengan Stone Grusher dengan spesifikasi campuran yaitu agregat $41 \%$ dan agregat $59 \%$. Agregat Klass B ini digunakan untuk perkerasan bahu jalan

Sebagai lapis pondasi yang akan Gradasi seragam (Uniform graded)

Mempunyai ukuran butir yang sama, tidak stabil dan kekuatan diperoleh dari kontak antar butir.

Yang harus dipenuhi oleh suatu material adalah :

Sebagai lapis pondasi yang akan memikul beban lalu lintas dan meneruskan ke lapis pondasi bawah, maka kualitas agregat adalah merupaka factor yang sangat penting. Untuk itu agar memenuhi persyaratan laboratorium, sehingga diketahui mutu agregat yang akan dipergunakan dan pengujian tersebut antara lain adalah sebagai berikut :

a. Gradasi dan ukuran butir

Syarat utama campuran agregat sebagai bahan konstruksi perkerasan jalan adalah gradasi yang dipakai akan menentukan kestabilan konstruksi jalan. Pada garis besarnya ada 3 (tiga) macam campuran agregat yaitu :

- Gradasi menerus (butir-butir halus mengisi pori-pori secara cukup), campuran ini mempunyai stabilitas tinggi, karena adanya interlocking yang baik antara agregat. Kekuatan diperoleh dari kotak antara butir dan stabilitas bisa ditingkatkan dari sifat-sifat kohesi butir halus yang mengisi void (ruang).

- Gradasi timpang (Gap graded) Sebagian ukuran butir hampir seragam, mempunyai sifat kurang stabil dan kurang 
kedap karena terdapat ruang antar agregat. Gradasi jenis ini lebih sesuai untuk agregat campuran hot rolled shet (HRS), karena mempunyai cukup ruang untuk bitumen.

b. Kekerasan / Keausan (strength and tougness)

Pada pekerjaan jalan, sebelum agregat mengalami proses pemecahan penghancuran dan penghalusan baik waktu crushing maupun pada waktu penghamparan dan pemadatan. Begitu pula halnya pada waktu agregat menerima beban lalu lintas, jika sifat kekerasan agregat tidak dipenuhi maka agregat bisa pecah dan jika hal ini terjaadi maka konstruksi perkerasan yang telah direncanakan tidak bisa mencapai umur rencana.

Pengujian ketahanan terhadap keausan di laboratorium dilakukan dengan mesin pengaus Los Angeles abrasion machine.

c. Ketahanan tarhadap pelapukan (soundness)

Pengaruh cuaca terhadap agregat sebagai bahan perkerasan akan menimbulkan pelapukan (weathering) begitu pula pengaruh kondisi lingkungan. Akibat konstruksi tidka awet / tahan, gradasi agregat berubah sehingga konstruksi perkerasan tidak stabil.

d. Tekstur permukaan

Susunan permukaan yang kasar akan mempunyai kecenderungan nambah kekuatan campuran bila dibandingkan dengan permukaan yang licin dan permukaan yang kasar akan menimbulknan ikatan yang baik antara butiran dan akan menimbulkan ikatan yang baik pula terhadap agregat dan bitumen yang kasar umumnya akan meningkatkan stabilitas dan keawetandalam campuran butimen.

e. Bentuk butiran

Bentuk butiran akan mempunyai beberapa pengaruh terhadap konstruksi perkerasan, terutama berpengaruh terhadap kemampuan pemadatan.

Bentuk butiran yang bulat / lonjong kurang membentuk bidang kontak antara agregat karena bidang sentuhnya hanya merupakan garis singgung atau titik,s ehingga terdapat ruang antara yang besar. Bentuk butiran yang pipih mempunyai peluang akan berubah bentuk butiran yang baik berbentuk kubus. Dalam pelaksanaan, batasan penggunaan bentuk butiran dipertimbangkan antara lain sebagai berikut :

- Untuk lapis pondasi bawah, bentuk butiran bulat masih bisa dapat dipergunakan.

- Untuk lapis pondasi entuk butiran bulat masih ada digunakan dengan batasan $40 \%$ agregat bulat tersebut minimal mempunyai satu bidang pecah.

- Untuk lapis permukaan butiran berbentuk bulat tidak diperbolehkan jadi seluruh agregat harus berbentuk kubus / pecah.

f. Absorsi

Pemeriksaan absorsi di laboratorium biasanya dilakukan bersamaan dengan proses pemeriksaan berat jenis.

Absorsi dan berat jenis nilai juga dapat dipakai untuk identifikasi kekuatan / kekerasan suatu agregat. Jika dibandingkan dengan sifat-sifat agregat lainnya maka absorsi tidak terlalu besar pengaruhnya tehadap kekuatan, tetapi berpengaruh dalam segi ekonomisnya apabila digunakan dalam campuran aspal beton.

Maksudnya adalah apabila absorsi besar maka aspal yang diserap oleh agregat tersebut akan menjadi besar pula sehingga diperlukan pemakaian aspal yang besar

g. Kebersihan 
Agregat yang akan dipergunakanuntuk konstrukai perkrasan harus bersih dari bahanbahan kotoran yang tidak dikehandaki yang dapat merugikan campuran perkerasan itu sendiri hal ini dalam persyaratan dibatasi.

Kebersihan agregat sering dapat ditentukan dengan pemerikasaan secara visual sedangkan di laboratorium digunakan dengan metode sand equivalent test, yang merupakan perbandingan relatif antara bagian yang merugikan terhadap agregat yang lolos saringan No. 4

h. Berat jenis

Penentuan berat jenis ini terutama dipergunakan untuk campuran aspal beton, untuk campuran agregat tanpa bitumen berat jenis tidak terlalu penting. Batasanbasatasan yang harus dipenuhi oleh agregat kelas A adalah sebagai berikut :

- Fraksi agregat kasar yang lolos ayakan $50 \mathrm{~mm}$ dana tertahan ayakan $4,75 \mathrm{~mm}$ harus terdiri dari partikel yang keras, awet dan jika dihasilkan dari kerikil maka tidak kurang dari $50 \%$ berat agregat harus terdiri partikel yang memiliki paling sedikit satu muka bekas pecahan dan jika kelebihan butir halus kerikil tersebut harus diayak.

- Fraksi agregat halus

Agregat halus yang lolos ayakan $4,75 \mathrm{~mm}$ harus terdiri dari pertikel pasir alami atau pasir pecah serta material halus lainnya.

\section{III . METODE PENELITIAN}

Perencanaan campuran beton untuk mendapatkan campuran beton yang memenuhi syarat - syarat sebagai berikut :

1. Kekenyalan tertentu yang memudahkan adukan beton ditempatkan pada cetakan / bakisting (workability) dan kehalusan muka (finishability) beton basah yang ditentukan dari :

a. Volume pasta adukan.

b. Keenceran pasta adukan.

c. Perbandingan campuran aggregat halus dan kasar.

2. Kekuatan rencana dan ketahanan (durability) pada kondisi beton setelah mengeras.

3. Ekonomis dan optimum dalam pemakaian semen.

Prosedur perencanaan adukan beton terdiri dari beberapa tahap pekerjaan :

1. Menetapkan konsistensi beton dengan SLUMP rencana berdasarkan Tabel. III-3.

2. Menetapkan ukuran maksimum aggregat kasar yang dipakai sesuai dengan jenis konstruksi dari Tabel.III-4.

3. Berdasarkan nilai SLUMP dan ukuran aggregat rencana, gunakan Tabel.III-5 untuk memperoleh jumlah air untuk setiap m3 beton, dan persentase udara yang terperangkap.

4. Dari dua penentuan nilai w/c ratio, yang masing-masing diperoleh atas batasan sifat ketahanan beton terhadap lingkungan (Tabel.III-1) dan atas kekuatan rencana beton (Tabel.III-2), gunakan nilai w/c ratio yang bernilai lebih kecil bagi perencanaan.

5. Jumlah semen dihitung dengan membagi besaran jumlah air yang diperoleh pada langkah 3 dengan nilai w/c ratio :

Jumlah semen $=$ Jumlah air ......(III-1)

$$
(w / c) \text { ratio }
$$

6. Dengan besaran diameter maksimum aggregat kasar dan nilai modulus kehalusan aggregat halus rencana, berdasarkan Tabel.III-6 ditetapkan persentase volume aggregat kasar/m3 beton. Berat total aggregat kasar yang digunakan diperoleh dari perkalian persentase volume dengan satuan berat aggregat.

7. Volume aggregat halus (pasir) dihitung dari selisih volume total beton dengan (volume semen + volume aggregat kasar + volume air dan udara yang terperangkap). Dengan nilai specific gravity yang diketahui, dihitung berat rencana aggregat halus. 
8. Jumlah unsur adukan untuk jumlah kubikasi beton tertentu dihitung atas dasar jumlah perlu bagi pengecoran.

9. Untuk kondisi lapangan, modifikasi bagi konsistensi w/c ratio disesuaikan dengan sifat bahan. Jika $\mathrm{G}$ merupakan berat bahan rencana yang diperoleh dari table-tabel, $\mathrm{m}$ adalah kadar kelembaban bahan dilapangan dan a adalah kemampuan absorpsi dilapangan ( $\mathrm{m}$ dan a dalam persentase), maka :

a. Tambahan air yang diperlukan $=$ $\mathrm{G}(\mathrm{a}-\mathrm{m}) /(1-\mathrm{m}) \ldots . . .(\mathrm{III}-2)$.

b. Tambahan aggregat yang diperlukan $=\mathrm{G}(\mathrm{m}-\mathrm{a}) /(1-\mathrm{m}) \ldots(\mathrm{III}-3)$

Adapun yang akan dilakasnakan penelitiannya adalah

- Analisa saringan agregat halus dan agregat kasar.

- Pemeriksaan kadar orgnanik dalam agregat.

- Pemeriksaan kadar lumpur dalam agregat $=3.7 \%<5 \%$

- Pemeriksaan kadar air Agregat Prosentasenya adalah 5,023\%

- Berat Voume Agregat kasar=1,57.

- Berat Volume Agregat Halus=1,5

- $\quad$ Spesisifik grafiti agregat halus $=2,5$

- $\quad$ Spesifik garafiti agregat kasar $=2,8$

- Perencanaan beton segar K250 atau Fc'20,75 Mpa.

\section{IV . ANALISIS DATA}

IV.1 Untuk benda uji campuran aggregat kasar batu pecah

- $\sum \sigma_{\mathrm{b}}=279.67+269.44+272.85+$ 266.03

$\mathrm{kg} / \mathrm{cm}^{2}$

- $\sigma_{\mathrm{bm}}=1087.99=271.99$

perhitungan kekuatan tekan beton yang didapat pada umur 28 hari

$\left(\sigma_{\mathrm{b}}^{\prime}\right)$ - kekuatan beton rata - rata $\left(\sigma^{\prime}{ }_{\mathrm{bm}}\right)$.

\begin{tabular}{|c|c|c|}
\hline $\mathrm{N}$ & $\begin{array}{c}\sigma_{\mathrm{b}}^{\prime}-\sigma_{\mathrm{bm}}^{\prime} \\
\left(\mathrm{kg} / \mathrm{cm}^{2}\right)\end{array}$ & $\begin{array}{c}\left(\sigma_{\mathrm{b}}^{\prime}-\right. \\
\left.\sigma_{\mathrm{bm}}\right)^{2} \\
\left(\mathrm{~kg} / \mathrm{cm}^{2}\right)\end{array}$ \\
\hline 1 & $279.67-271.99=7.68$ & 58.98 \\
\hline 2 & $269.44-271.99=-2.55$ & 6.50 \\
\hline 3 & $272.85-271.99=086$ & 0.74 \\
\hline 4 & $266.03-271.99=-5.96$ & 35.52 \\
\hline
\end{tabular}

Nilai deviasi standar benda uji :

$$
\begin{aligned}
& \mathbf{S}=\sqrt[101.74]{4-1}=5.82 \mathrm{~kg} / \mathrm{cm}^{2} \\
& \text { Kekuatan tekan karakteristik beton : } \\
& \begin{array}{l}
\sigma_{\mathrm{bk}}^{\prime}=\sigma^{\prime}{ }_{\mathrm{bm}}-1.64 . \mathrm{S} \\
=271.99-(1.64 \times 5.82)=\mathbf{2 6 2 . 4 4} \\
\mathbf{~} \mathbf{g} / \mathbf{c m}^{2}
\end{array}
\end{aligned}
$$

IV.2 Untuk benda uji campuran aggregat kasar batu alam :

- $\sum \sigma_{\mathrm{b}}=252.38+255.80+255.80+$

$262.62=1026.60 \mathrm{~kg} / \mathrm{cm}^{2}$.

- $\sigma_{\mathrm{bm}}=\underline{1026.60}=256.65 \mathrm{~kg} / \mathrm{cm}^{2}$

4

Tabel (IV-4) Kekuatan tekan beton masing umur 28 hari $\left(\sigma^{\prime}{ }_{b}\right)-$ Kekuatan tekan beton rata-rata $\left(\sigma^{\prime}{ }^{\prime}\right.$ m $)$

\begin{tabular}{|l|l|c|}
\hline & \multicolumn{1}{|c|}{$\begin{array}{c}\sigma_{\mathrm{b}}^{\prime}-\sigma_{\mathrm{bm}}^{\prime} \\
\left(\mathrm{kg} / \mathrm{cm}^{2}\right)\end{array}$} & $\begin{array}{c}\left(\sigma_{\mathrm{b}}^{\prime}-\sigma_{\mathrm{bm}}^{\prime}\right) \\
{ }^{2}\left(\mathrm{~kg} / \mathrm{cm}^{2}\right)\end{array}$ \\
\hline 1 & $\begin{array}{l}252.39-256.65= \\
-4.26\end{array}$ & 18.23 \\
\hline 2 & $\begin{array}{l}255.80-256.65= \\
-0.85\end{array}$ & 0.72 \\
\hline 3 & $\begin{array}{l}255.80-265.65= \\
-0.85\end{array}$ & 0.72 \\
\hline 4 & $\begin{array}{l}262.62-256.65= \\
5.97\end{array}$ & 35.64 \\
\hline & Jumlah & 55.31 \\
\hline
\end{tabular}

Nilai deviasi standar benda uji :

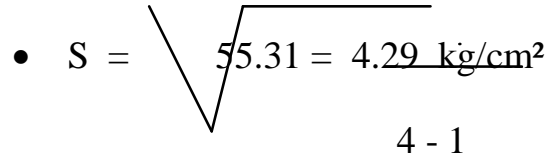

Kekuatan tekan karakteristik beton :

- $\sigma_{b \mathrm{bk}}^{\prime}=\sigma_{\mathrm{bm}}^{\prime}-1.64 . \mathrm{S}$

$=256.65-(1.64 \times 4.29)$

$=250.61 \mathrm{~kg} / \mathrm{cm}^{2} / 21,30 \mathrm{mpa}$

\section{V . IMPULAN DAN SARAN}

\section{SIMPULAN}

Dari perhitungan dan analisa data percobaan maka dapat disimpulkan bahwa karakteristik campuran struktur beton dalam pemakaian aggregat kasar yang berbeda antara batu pecah dengan batu alam, dengan ketentuan yang sama dan K 250, yang dilakukan dalam penelitian ini adalah sebagai berikut : 
1. Untuk benda uji campuran beton aggregat kasar batu pecah, hasil percobaan yang didapat nilainya sebagai berikut :

- Kekuatan tekan beton rata - rata $\left(\sigma^{\prime}{ }_{b m}\right)=271.99 \mathrm{~kg} / \mathrm{cm}^{2}$.

- Nilai standar deviasi benda uji ( $\mathrm{S}$ )

$=5.82 \mathrm{~kg} / \mathrm{cm}^{2}$.

- Nilai tekan beton karakteristik $\left(\sigma^{\prime}{ }_{\mathrm{bk}}\right)$

$=262.44 \mathrm{~kg} / \mathrm{cm}^{2}$.

- Kekuatan tekan beton rencana ( K )

$=250 \mathrm{~kg} / \mathrm{cm}^{2}$.

2. Untuk benda uji campuran beton dengan aggregat kasar batu alam.

Hasil penelitian yang didapat nilainya sebagai berikut :

- Kekuatan tekan beton rata - rata

$\left(\sigma^{\prime}{ }_{b m}\right)=256.65 \mathrm{~kg} / \mathrm{cm}^{2}$

- Nilai deviasi standar benda uji

$$
(\mathrm{S})=4.29 \mathrm{~kg} / \mathrm{cm}^{2} \text {. }
$$

Kekuatan tekan beton karakteristik $\left(\sigma^{\prime}{ }_{\text {bk }}\right)$ $=250.61 \mathrm{~kg} / \mathrm{cm}^{2} \cdot / 21,30 \mathrm{Mpa}$

Kekuatan beton rencana

$(\mathrm{K})=250 \mathrm{~kg} / \mathrm{cm}^{2} .=21,3 \mathrm{Mpa}$

\section{SARAN - SARAN}

1 Untuk mendapatkan mutu beton yang lebih baik, sebaiknya dilakukan pengujian dengan metode yang lain, seperti K 275/22,9 Mpa dan K 300/24,9Mpa .

2. Didalam pengujian hendaknya dilakukan dengan bahan yang berbeda seperti aggregat batu pecah dengan ukuran yang lain maupun aggregat batu alamnya, untuk lebih mengetahui tentang kekuatan beton dengan campuran aggregat kasar yang bebeda.

3. Dalam melakukan penelitian dilaboratorium pengendalian (kontrol) terhadap bahan campuran beton lebih diketatkan atau teliti.

4. Untuk melaksanakan sebuah konsturksi struktur beton yang mempunyai beban yang sangat besar atau kuat tekannya besar ada baiknya untuk pemakaian aggregat kasar batu pecah karena telah kita teliti dilaboratorium aggregat kasar batu pecah lebih besar kekuatan tekannya dibandingkan dengan aggregat kasar batu alam.

\section{DAFTAR PUSTAKA}

- PBI 1971 dan Skni 2002.

- Sukirman, Silvia ,1992, Perkerasan lentur Jalan Raya, Penerbit Nova Bandung.

- Sukirman , Silvia 2007, Beton Aspal Campuran panas, Edisi ke 2 Penerbit Obor Indonesia , Jakarta 